so many vague and highly anomalous reports from the Himalayas ${ }^{34.36-38}$, which are unlike his works from other areas. Until 1988 no foreigners were allowed into Spiti, and when they were allowed to do so (as were Talent, Fuchs and a few others) they had to be accompanied by Indians.

Allegations of recycling of fossil specimens by assigning fictitious locality labels, or using foreign materials once housed in foreign museums ${ }^{25}$ to illustrate 'new dis- coveries' from the Himalayas, are indeed serious and are being treated as such at Chandigarh, contrary to the report by Jayaraman $^{39}$. Not only Gupta but also Waterhouse must speak up honestly and boldly, and address the grave charges point by point, as the issues involved can no longer be evaded.

A.D. Ahluwalia is in the Centre of Advanced Study in Geology, Panjab University, Chandigarh - 160014, India.

\section{Early Devonian ostracodes}

\section{S. B. Bhatia}

I would like to take this opportunity of placing on record facts concerning the precise locality from which the Early Devonian ostracodes, reported by myself and my colleagues V.J. Gupta and S.P. Jain $^{1}$, were collected, and to which Talent referred in his Commentary article. I was a member of the expedition (along with Gupta, Jain and R.C. Kanwar) which visited the Spiti Valley in 1966, and in the last leg (on which Jain was not present) I collected samples from near Kurig, close to the India-Tibet border. But the sample in question (containing ostracodes) was not collected by me. I also do not recollect Gupta collecting samples from that area.

However, several years later, in 1972, when I was about to visit Britain under a British Council Exchange Programme, Gupta handed over to me a small vial containing some washed residue and asked me to have a look at the ostracodes it contained during my stay at the British Museum (Natural History). Gupta stated that the sample was from near Kurig, without being precise, and of Devonian age. My own observations in the field diary, however, were that the rocks around Kurig were of Permo-Carboniferous age. I accepted Gupta's statement in good faith, presuming that I had missed the band containing Devonian ostracodes.

While working at the $\mathrm{BM}(\mathrm{NH})$ I was struck by the close similarity and even match, at the specific level, of the material provided by Gupta and the material from the Haragan Formation, Oklahoma, housed in the $\mathrm{BM}(\mathrm{NH})$. Accordingly, a slide containing representative ostracodes was sent to Dr Lundin of Arizona State University for his comments, and he too was impressed by the similarity of the Spiti and Haragan faunas.

Be that as it may, as a sequel to the controversy raised by Talent it became imperative for me to recheck the possible match of the Spiti and the Haragan ostracode faunas. Accordingly, I requested Lundin (in a letter of 12 April 1989) for some comparative material from the Haragan. I await that material, but can quote from Lundin's letter of 2 May 1989:

I have followed the controversy brought on by Gupta's discoveries and the article by Talent with great interest especially because of the ostracodes you sent me in 1972. I recall that I was especially impressed at the similarity of the fauna you sent me with the Haragan fauna I described in 1968. The species constitution and the Haragan fauna, as I recall, were remarkably similar. Scientists are skeptics! As well they should be. I regret that your name has been tarnished.

The facts mentioned above are being communicated so that the scientific community may know the truth regarding the worth of 'Devonian ostracodes' from the Himalayas in the context of the controversy regarding the authenticity of Gupta's research findings. As stated in the editorial on p.604 of the same issue of Nature as Talent's article, palaeontologists should, on this occasion, have been quicker to voice their doubts. True, but then it is better to be late than never.

Finally, I should like to comment on the news story by Jayaraman which later appeared in Nature . $^{2}$

Jayaraman's contention that Gupta's colleagues at the Centre of Advanced Study in Geology, Panjab University, Chandigarh, consider Talent's allegations as a "conspiracy to denigrate a top Indian scientist" is not true. I, for one, reacted immediately to the controversy, and in a letter dated 27 April 1989, addressed to our Vice-Chancellor, I suggested that a fact-finding committee should be set up to get to the truth. In fact, as stated in this letter, I am firmly of the opinion that the only way in which the scientific community will be convinced of Gupta's research findings will be for Gupta to invite some Earth scientists to accompany him to a few of the controversial localities in the Himalayas and prove the authenticity and reproducibility of his fossil finds. This is the only way Gupta can redeem his reputation as well as the fair name of our university.

S. B. Bhatia is in the Centre of Advanced Study in Geology, Panjab University, Chandigarh160014, India. 1. Bhatia, S.B., Jain, S.P. \& Gupta, V.J. Geol. Surv. India
Misc. Pub. 41, 285-292 (1982). even the state of preservation of your fauna and

2. Jayaraman, K.S. Nature 338, 694 (1989).

\section{The Kinnaur region}

Udai K. Bassi

THE Kinnaur region of the Himalayas is the subject of some of the questionable papers discussed by Talent. This inhospitable and rugged terrain was systematically mapped and investigated by myself and my associates during nine expeditions (1978-86), each expedition lasting over a hundred days. Based on my intimate knowledge of Kinnaur and part of Spiti, I make the following observations on publications dealing with this area.

(i) It would be impossible to obtain the Devonian ostracode fauna' from Kurig, for in this area only Carboniferous rocks are exposed ${ }^{2}$.

(ii) The report of Late Devonian vertebrate remains ${ }^{3}$ from the Yulang section states: "Muth Quartzite passes up into a $50 \mathrm{~m}$ thick succession of shales with thin bands of quartzite followed by a $200 \mathrm{~m}$ thick horizon of siliceous and shaly limestone". Another paper on the same area states: "The Muth Quartzite in the Yulang River section is conformably overlain by $10 \mathrm{~m}$ thick succession of grey limestone forming transitional horizon between the Muth Quartzite below and Lipak Formation above". The lithostratigraphy in the two reports is not only contradictory but factually incorrect - the sequence in the Yulang section is inverted and the Muth is physically overlain by the Silurian Takche Formation. Moreover, Gupta reported the same conodont fauna (Palmatolepsis, Polygnathus and so on), from two limestone horizons separated by $50 \mathrm{~m}$ and resting above the Muth Quartzite ${ }^{3.4}$. The anomalies in lithostratigraphy and fauna levels render these two papers worthless.

(iii) The description of the geology of the Tidong Valley ${ }^{5}$ surprisingly lacks a geological map and contains a borrowed lithocolumn'. It also omits details of the pre-Muth sequence, which is best developed in this section?. The report of sulcispiriferinids $^{*}$, ignoring the work of Chopra et al. ${ }^{6}$ and referring to Gupta and Waterhouse ${ }^{5}$ with a wrong title, is mystifying.

(iv) The paper on the Fammenian ammonoids $^{y}$ post-dates all papers on Khimokul La yet it avoids all references to this work, even Gupta's own earlier papers. The "limestone" or "shale" bands referred to in the Muth Formation in this section are fictitious and do not exist in the field. The paper declares that the repository of the ammonoids is the Geology Department at Panjab University, but no registration numbers are given. Enquiry at the Geology Department revealed that these specimens were never deposited there.

The statement "Noric and Rhaetic suc- 